\title{
Sección Especial: Desarrollo Cívico
}

\section{Special Section: Civic Development}

\author{
María Loreto Martínez \\ Editora Invitada
}

\section{Introducción}

El conocimiento acerca del desarrollo y fortalecimiento de la ciudadanía es un área de creciente interés en todo el mundo, por las implicancias que este tiene para el bienestar de las sociedades y la sustentabilidad de los sistemas democráticos. Como noción y como práctica, la ciudadanía es histórica y cultural; es decir, está anclada en las características culturales de cada sociedad y evoluciona de acuerdo a los cambios que se producen en las sociedades a lo largo de la historia.

A fines del siglo XX los cambios asociados a la globalización, al acceso a tecnologías de comunicación y las características de los sistemas económicos prevalecientes modificaron las visiones de sociedad y las formas de participación en ella. A nivel del individuo como agente social, de la organización comunitaria y de las instituciones de la sociedad, estos cambios plantean el desafío de repensar la ciudadanía y los procesos relacionados con esta, como son la participación social y política y el empoderamiento de grupos, particularmente de aquellos que puedan ver vulnerados sus derechos.

El propósito de esta sección especial de Psykhe es difundir y discutir hallazgos de estudios empíricos sobre el desarrollo cívico de jóvenes y analizar aspectos teóricos del fortalecimiento de su ciudadanía a nivel de la sociedad. En toda sociedad, los jóvenes son la generación llamada a forjar un nuevo orden cívico; colaborando con la generación adulta, los jóvenes podrán integrar la tradición con la renovación para construir la sociedad del futuro. Existe consenso de que los jóvenes se han distanciado de formas convencionales de participación política y han mostrado nuevas formas de participación social, cuyas motivaciones y potenciales resultados han sido poco estudiados. Los dos estudios empíricos incluidos en esta sección enfatizan las experiencias y visiones de los jóvenes como actores ciudadanos. Desde una perspectiva cualitativa, se proponen comprender de qué manera las experiencias de participación social de los jóvenes se relacionan con sus actitudes, identidades y compromisos cívicos en diferentes contextos nacionales (Italia y Chile) y culturales.

Por implicar tanto aspectos de los individuos en tanto ciudadanos como de los sistemas sociopolíticos, la investigación en ciudadanía requiere la participación de diferentes perspectivas disciplinarias. Por lo anterior, los artículos de esta sección representan diferentes perspectivas de la psicología (evolutiva, social, comunitaria y política) y la economía política. Para facilitar el análisis de los hallazgos se incluye una discusión crítica de cada estudio que sugiere preguntas y releva temas para futuros estudios.

A través de entrevistas en profundidad, Marta, Pozzi y Marzana identifican perfiles de voluntarios en jóvenes adultos y los factores que dan cuenta de la duración de su compromiso cívico. Cadena analiza los aportes y limitaciones de la perspectiva multidimensional de Marta et al. para la comprensión de las motivaciones de los jóvenes voluntarios. Martínez, Silva y Hernández analizan las creencias, motivaciones y aspiraciones de ciudadanía en una muestra de jóvenes chilenos con historia de compromiso cívico, analizando los valores asociados a las concepciones de los jóvenes y sus implicancias para su integración activa como ciudadanos. Desde una perspectiva de la economía política, Silva y Silva analizan los hallazgos de Martínez et al. y los relacionan con la 
estructura de los sistemas económicos y el modelo político de la sociedad. Finalmente, desde una perspectiva teórica, Montero analiza los puntos de encuentro y los aportes de la psicología comunitaria y la psicolo- gía política al fortalecimiento de la ciudadanía y la transformación social, analizando los conceptos de poder y empowerment, las implicancias para las políticas públicas y la intervención psicosocial y comunitaria. 